\title{
¿CÓMO PUDO SUCEDER? EN TORNO A LA TOMA DEL PODER NAZI EN ALEMANIA
}

\section{¿HOW COULD IT HAPPEN? ABOUT THE NAZI POWER SEIZE IN GERMANY}

\author{
Claudio Llanos Reyes ${ }^{*}$
}

\section{RESUMEN}

A setenta años del inicio de la segunda Guerra mundial, las causas que hicieron de Alemania uno de los principales actores de la tragedia, continúa siendo un punto de debate y analisis. El presente trabajo intenta aproximarse a las miradas actuales que desde la historiograffa inglesa actual buscan dar explicación y comprender mejor la toma del poder por parte de Hitler en Alemania. Comprender este periodo es relevante en cuanto a su peso histónico en la constitución de la unidad de Europa. El proceso de crisis vivido en Alemania durante la República de Weimar es tanto el antecedente inmediato de la captura del poder por parte de los nazis, como una de las causas, post-segunda guerra mundial, de la búsqueda de unidad europea. Asi, el miedo al regreso del pasado de crisis es parte constituyente del origen de una Europa que ha logrado ir superando las causas de la "guerra total".

Palabras clave: Alemania, nazis, dictadura, historiografia británica.

\section{ABSTRACT}

Seventy years after the end of the second world war, the causes that they made Germany one of the main actors in the tragedy contimues being a point of discussion and analysis This paper attempts to get closer to the current looks from the current English historiography. looking for explanation and understanding of the capture of power by Hitler in Germany. Understanding this period is relevant in its historical weight in the Constitution of the unity of Europe. The process of crisis lived in Germany during the Weimar Republic is both the immediate antecedent of the eapture of the power of part of the nazis, as one of the causes, the post Second World War, the search for a European unity. Fear of the return of the past of erisis is part of the origin of a Europe that has managed to go overcoming the causes of the "total war".

Keywords: Germany, Nazis, dictatorship, British historiography.

\section{INTRODUCCIÓN}

El presente trabajo intenta aproximarse a las miradas actuales que desde la historiografía británica actual buscan dar explicación y comprender mejor la toma del poder por parte de Hitler en Alemania ${ }^{1}$. Así, aproximarnos mejor a la comprensión de este periodo permite incluso, siguiendo la idea de Tony Judt, entender el origen de la Unión Europea, pues ella nace, en parte, del miedo al retorno a un pasado que con sus crisis, desempleo y divisiones llevó a Europa y a la humanidad a uno de sus momentos más oscuros?

- Doctor en Historia, Seminario Interdisciplinario de Investigación, Pontificia Universidad Católica de Valparaiso.

1 Para esto resultan de primera relevancia los diversos trabajos publicados en ios áltimos afos en el fournal of Contemporary History (Sage Publications Londres). Se debe apuntar ademais que desde el aho 2003 las opiniones del embajador de Alemania en Inglaterra (Thomas Matussek) sobre la permanencia de una idea de Alemania anclada en la Segunda Guerra mundial y que debe ser corregida, pues a juicio del entoncer embajador germano en Inglaterra las ideas de los britinicos sobre Alemania estaban marcadas por el pasado sin considerar los avances y cambios sucedidos desde 1945. Sobre este tema la imagen estereotipada parece estar siendo dejada atrás si bien no totalmente-por lo menos a nivel académico.

2 Jundt, T. 2005, Postguerna. Una historia de Europa desde 1945, Madrid, Taurus. En el articulo uno del Consejo de Europa (1949) se señalaba la búsqueda del objetivo, no cumplido antes, de lograr la cooperación entre los paises europeos. 
Este "estado de la cuestión" reconoce que el ascenso al poder por parte de los Nazis ha sido una preocupación que ha recibido atención desde el momento mismo de la llegada del Führer al poder y que ha ocupado a investigadores de diversas tradiciones y nacionalidades ${ }^{3}$.

Desde la segunda mitad del siglo XX las miradas se han centrado en las cuestiones de gobierno; los personajes que fueron actores principales de 1933 a 1945 y los horrores de Holocausto. Éstas se encontraban enmarcadas en un contexto caracterizado por la guerra fria, la división de Alemania, la existencia de la Unión Soviética y los crímenes contra la humanidad cometidos por el régimen Nazi.

En los últimos años, en los temas abordados por la investigación británica logra apreciarse un enriquecimiento y profundización de las miradas que configuran un movimiento desde interpretaciones históricas que intentan comprender de forma más global los diversos elementos que dentro de la sociedad alemana le permitieron a Hitler y su partido (NSDAP o Nazis) apoderarse del Estado y establecer una dictadura ${ }^{4}$. $\mathrm{Y}$ si bien aún hoy se pueden reconocer algunas persistencias de las ideas de Churchill y los aliados sobre el "peligro alemain" ya no son las únicas.

Durante las últimas décadas del siglo $\mathrm{XX}$, una nueva tendencia vio la luz con claridad, ahora se iniciaba el escrutinio sobre los temas histórico-sociales que explicaban la dictadura, su llegada al poder y su desarrollo. Quizá en este cambio de rumbo tuvo un rol la nueva configuración del propio mapa de Europa.

Los cjes de interés y las preocupaciones tendieron a cambiar al ritmo de la demolición del muro de Berlín, la reunificación de Alemania, la caída de la Unión Soviética y la consolidación de la Unión Europea. Después de todo, la "responsabilidad histórica de Alemania" o su "continuo error" no podían sostenerse al ver una Comunidad Europea que tiene como uno de sus pilares principales en lo político y lo económico a una Alemania unificada. Al mismo tiempo trazar una línea que igualara al Estado Nazi con el pueblo alemán, en general, era demasiado arbitrario como para ser sostenido. A nivel general se comenzó a ver un enriquecimiento, con los estudios sobre la resistencia al interior de Alemania y de las víctimas no judías del régimen 5 .

En esas nuevas miradas británicas - no libres de vacíos - se adentra este trabajo, en aquellas que intentan enseñarnos como una sociedad traumatizada por guerras, acusaciones, castigos y crisis se vio atrapada en un nueva espiral de opresión, violencia y guerra.

\section{¿CÓMO PUDO SUCEDER?}

"En el nacionalsocialismo todo es tan contradictorio y cá́tico como en una pesadilla. El partido de Hitler se llama a sí mismo socialista; sin embargo, lleva una lucha terrorista contra todas las organizaciones socialistas. Se llama a sí mismo partido obrero; sin embargo, sus filas abarcan a todas las clases excepto al proletariado. Arroja sus dardos relampagueantes a las cabezas de los capitalistas; sin embargo es apoyado por ellos. Se inclina ante las tradiciones germánicas; sin embargo aspira al cesarismo, una institución enteramente latina. Con sus miradas vueltas hacía Federico II, Hitler imita los gestos de Mussolini...con un bigote a lo Charlie Chaplin" 6 .

\footnotetext{
3 Es necesario serialar que dentro de Alemania y durante fines de la década de 1970 e inicios de la del 1980 Erns Nolte desató un importante dehate (Histarikestreif) al interpretar el Holocausto como una reacción "hasta cierto punto comprensible" pero "exugerada" de Hitler a la amenaza soviética. Ver: Nolte, E 1967. El foscismo en su época, Barcelona, Edicions 62. Una década antes el historiador Fritz Fisher habia desatado la polémica al plantear la responsabilidad histórica de Alemania en la primera guerra mundial y su "continuo erros" en la politica europea. Ver: Sabrow, M. et all. 2003. Zeit Geshichte als Strvitgeschichte. Grossen Kontroversen seit 1945, Munich, Editorial C.H. Beck.

Las respuestas al interior de Alemania a estas interpretactones de "culpabilidad" han centrado su atención en las responsabilidades de Versalles o en la politica "contrarrevoluciotratia" de la Republica de Weimar.

Desde la sociologia politica Nicos Poulantzas planteó la toma del poder por parte del Partido Nazi como resultado inesperado de la politica zigzagueante de socialismo en un solo pais de la Tercera Internacional dirigida por Stalin. Todo esto en un escenario de crisis capitalista y ajuste imperialista. Ver: Poulantzas, N, 1976. Fascismo y Dictadura. La Tercera Internacional Frente Al Fascismo, Barceiona, Editorial Siglo XXI. En el marco de las miradas inás generales, los trabajos reconocen la importancia de las crisis económicas de 1923 y 1929 durante la Weimar Repubik en el ascenso de Hitler al poder, asignado diverso grado de importancia a las condiciones de vida de los sectores asalariados y a la fuerte acumulación de riqqueza por parte de los sectores industriales y especuladores. Ver por ejemplo: Ver por ejemplo: PARKER. R. A. C. 1978, EI Siglo XX. Ėuropa, 1918-1945, México, Siglo XXI Editores; HOBSBAWM, E, 2006. Historia del Siglo XX, Barcelona, Critica.

4. Tal desplanamiento se puede observar en la "reaponsabilidad histórica" planteada a partir del trabajo de Fisher. Fritz. 1961 . Griff nach der Weilmacht. Die Kricgsszicipolitik des katiseriichen Deutschland 1914/1918, Disseridorf.

5. Entre los diversos trabajos: Stoltzfus, N. 2001. Resistance of the Heart Intermarniage and the Rasenstnasse Protest in Nazi Germany, Rutgers University Press; Blair, S. 2002. Resisting Hitler: Mildred Harnack and the Red Orchestra, Oxford Univ. Press, Nelson. A. 2009. The Red Orchestra, Random House, Newborn, I y Bumbach, A. 2006. Sophie Scivoll and the With Rose. Oneworld Publ.

- Trotsky, L 1980. La Lucha contra d fascismo. El proletariado y la revolacidn, Fontamara, Barcelona, p. 169.
}

Revista de Historia, año 18, vols. 18-19, 2008-2009, pp. 69-78. 
Considerando las distancias y limitaciones que un observador inmediato puede tener, la caracterización hecha por Trotsky de Hitler y su partido en 1932 nos introduce en el problema de cómo una organización como el Partido Nacional Socialista Obrero Alemán (NSDAP o nazi) pudo llegar al poder, qué factores al interior de la sociedad alemana facilitaron que por la vía democrática se instalará en el poder una organización que despreciaba este sistema.

En la respuesta a esta pregunta es innegable reconocer la presencia de continuidades, cambios y por supuesto de enriquecimientos interpretativos permanentes. De las lecturas realizadas hasta ahora a la abundante cantidad de artículos publicados en diversas revistas británicas de historia se pueden extraer algunas tendencias o temas centrales en las miradas sobre la sociedad alemana previa al ascenso de Hitler al poder y la instauración de la dictadura nazi. De éstas este trabajo se referirá a: el peso de la guerra y el culto militar al soldado; la violencia polftica y racial y la búsqueda del orden social y la falsificación del pasado. Se agrega además al final una mirada a la base material del éxito de Hitler, tema tratado en abundancia pero en el que nuevas luces aparecen particularmente en relación al desempleo y las políticas de Weimar sobre éste.

\section{LA GUERRA Y EL CULTO AL SOLDADO}

El conjunto de la literatura sobre las causas del rápido acenso de Hitler reconoce que la Prímera Guerra Mundial, su propio desarrollo y consecuencias jugaron un rol central en el proceso de configuración tanto del Partido Nacional Socialista Obrero Alemán (NSDPA o nazi) como en su "éxito" en 1933 y su consecuente dictadura.

Richard Bessel ${ }^{7}$ muestra el peso y significado social de la Gran Guerra en la sociedad alemana: "el trauma de la guerra"8. Una de las consecuencias importantes en la interpretación de Bessel no es simplemente la frustración de un país derrotado y castigado por los acuerdos de Versalles y la Paz de Paris ${ }^{9}$, sino que la militarización de la sociedad ${ }^{10}$. Así, la figura militar ocupaba después de la primera guerra un importante espacio dentro de la cultura político - social alemana, Hitler se presenta como un simple frontsoldat apoyado por los grandes héroes militares alemanes como Hindenburg. Esto no era menor toda vez que "sobre 10 millones de veteranos del servicio militar durante la Gran Guerra sobrevivieron el conflicto y estaban en condiciones de votar en las elecciones de 1932 y $1933 \% 11$.

Para los sectores conservadores y derechistas de la política y la sociedad alemana entre 1918-1933 la figura del miliar y del ejército no era la de una fuerza derrotada por las fuerzas aliadas de la Gran Guerra. En su interesada lectura de la guerra y su final, la revolución de noviembre de 1918 había significado una "estocada por la espalda" (Dolchstoß) a la fuerza militar germana. Esto pasó a ser un mito dentro de la derecha alemana (Dolchstosslegende). Para ésta la "traición" había sido dirigida por los sectores de izquierda, catalogados como los "criminales de noviembre" (Novemberverbrecher). Por cierto, la izquierda habia visto en la guerra el sufrimiento y la muerte del pueblo producto de la política de unos embusteros sin escrúpulos 12 y la necesidad de instaurar un nuevo régimen, una República.

Antes de 1933, el culto al militar era una actividad incentivada desde el Estado Imperial alemán, una construcción desarrollada a partir de un complejo entramado ritual existente en cada uno de los estados alemanes, aún después de la unificación en 1871. Alastair Thompson ha problematizado este elemento de continuidad, señalando que esta "obsesión" por los honores puede estar ligada a la existencia de complejos de superioridad locales - particularmente la burguesía protestantes del norte- y de un intenso sentido de división social y de su propia posición ${ }^{13}$.

\footnotetext{
7 Richard Bessel es profesot de Historia del siglo XX en la Universidad de York. Inglaterra.

* Entre los estudios sobre las consecuencias traumáticas de la guerra en la sociedad alemana se encuentra: Crouthamenl, J. 2002. "War Neurosis versus Saving Psychosis; Working class Politics and Phychological Trauma in Weiraar Germany", en journal of Contemporary History, vol 37 (2). pp. 163-182. También, aunque con una mirada más general sobre el tema: Leed, E. 2000. "Fateful Memories: Industrialized War and Traurnatic Neuroses", en Journal of Contemporary History, vol. 35 (1), pp. $85-100$.

- Ver: Parker, R. A.C. Ope cit

ie Bessel, R. "The Nazi Capture of Power", en Journal of Centemponiry ffistory, Vol 39, (2), Sage Publication, 2004, pp. 173 ss.

11 Jbid, p. 173.

12 Parker, R, A. C., Op, cit. pp. 243-244.

13 Thompson, A. 1994. "Honours Uneven: Decorations, the State and Bourgeois Society in Imperial Germany", en Past and Present, Oxford University Press, 144, pp, 171-204.
} 
El culto al militar, al soldado se encuentra en los monumentos levantados a los caídos en la Gran Guerra. Stefan Goebel ${ }^{14}$, apunta que la idea del monumento era el "intento de revivir a los muertos para ayudar a los vivos" 15 . Asi los muertos se constituían como una suerte de guardianes de la memoria de la guerra. Memoria que podía, a largo plazo, fundirse con el interés nacionalsocialista de revivir a los soldados "traicionados". Constituían vengadores durmientes,

"Paz profunda rodea el sitio donde el libro (del recuerdo) se colocará. Se irradia desde la figura del Guerrero con el casco de acero que descansa allí de la batalla y la lucha. No le robemos a él y a ellos esta paz; han hecho lo que podían y están bien ahora. Su sacrificio, su abandono y devoción por desgracia no han asegurado la recompensa que los caidos y nosotros esperábamos. Nuestra patria ha perdido una buena cantidad de honor, de libertad y de poder, porque nos retiramos antes de haber sacrificado nuestros (hijos) más grandes y últimos, porque no hemos demostrado ser dignos de la sangre que ellos derramaron por nosotros. Por lo tanto, reparemos lo que hemos arruinado; borremos las letras escritas desde sus muertes en el libro de historia, tomemos una nueva hoja y escribamos lat palabra de la patria santa en ella. Asf despertamos a los dormidos de su sueño, así descenderán para ayudarnos a vivir, sufrir y luchar y ganar, así cumpliremos con las palabras 'Un hombre no tiene mayor amor, que el hombre que da su vida por sus amigos ${ }^{\prime \ldots 16}$.

En el contexto de la construcción de una imagen virtuosa del militar, el "culto" al soldado, particularmente en los sectores conservadores y en la derecha alemana es un factor que permite explicar lo que Kershaw 17 observó en tomo a la figura del Führer "personificación de los objetivos del régimen y el consecuente culto a su persona" 18 , Según Kershaw esto tiene una central importancia, pues

"No Hitler: no SS - police state (...). No Hitler: no general European war by the late 1930s. No Hitler: an alternative war strategy and no attack on the Soviet Union in 1941 (...). No Hitler: no Holocaust...."19.

En un plano más general el culto al líder constituía un elemento compartido por los dos partidos fascistas más representativos, el Partido Nacional Fascista de Italia y el nazi, que en sus líderes "omnipotentes" planteaban la capacidad de control sobre la sociedad (y sus propios seguidores) 20 .

La relevancia de la personalidad de Hitler ocupa - en general - un puesto importante dentro de los estudios sobre el fascismo alemán, su crecimiento, el establecimiento de la dictadura nazi y la guerra. Pero el factor personal no debe hacer perder la perspectiva histórica y sobre ésta se debe señalar el trabajo David Blackbourn "The Polítics of Demagogy in Imperial Germany"21, donde se muestra la continuidad que tuvo el discurso demagógico dentro de la política alemana desde antes de 1914 hasta la aparición del NSDAP y su figura central: Hitler. Blackbourn apuntó, además, la continuidad organizativa desde órganos "proto fascistas" reconocibles antes de 1914, como la Liga Agraria y la Liga Pan germánica 22 . En este marco, la demagogia no habria sido acto de manipulación sino que un recurso habitual de la elite alemana (desde el reinado de Wilhem y la Republica de Weimar) para recolectar fuerzas sociales y políticas difíciles de controlar totalmente 23 .

En medio de una crisis económica, con aumento del desempleo y de las críticas al sistema capitalista el NSDAP se present6 como la alternativa, la "salvación de la nación alemana", frente al "peligro comunista". Los Nazis y su líder más carismático Hitler apuntaron a la "refundación de la nación", tomando así uno de los elementos centrales de la ideología fascista, con la particularidad - según Kernshaw - de que en Alemania esta idea asumió fuertes connotaciones pseudoreligiosas ${ }^{24}$. Para tal "refundación" la militarización de la sociedad era un elemento indispensable, pues brindaba un marco de aceptación de la violencia y la represión que

\footnotetext{
14 Stefan Goebeh, era hasta el año 2004 estudiante de postdoctorado del lnstituto de Investigación Histórica en Londres y miembro investigador del Churchill College, Cambridge.

is Goebel, S. 2004. "The 'Sleeping Dead' in Interwar and Britain", en lournal of Cunteniponary Hisfory. Vol. 39 (4). p. 491.

14. Llamado del 75* Regimiento (75 er Regiments - Appell), Brenen Nachrichten, no. 263, suplemento, 21 de septiembre de 1924. Citado por Goebel. S. Op.cit. p. 491. (Traducido por el autor).

17. lan Kershaw es profesor de Historia Moderna en la Universidad de Sheffield, Inglaterra.

18 Kershaw, I. 2004. "Hitier and the Uniqueness of Nazism". En: lournal of Contemporary History, Vol. 39 (2), pp. 245 y ss. Tambièn Kershaw desarroila esta idea ea Hitler, Península, 2007 (des tomos);

19 Ibid, p. 254.

20 Kallis, A. 2004. "Consensus' Ideological Production, Polirical Fxperience and the Quest for Studying Inter-War Fascism in Epochal and Diachronic Termst, en Europaan History Quarterly, 34 (9), p. 19.

21 Blackbourn, D 1986, "The Politics of Demagogy in Imperial Germany". en Past and Present, no, 113, pp. 152-184.

2 Tbid, pp, 153-154.

23 Ibid, p. 113.

26 Kershaw, L. "Hitler and the Uniqueness of Naztsm.... p. 247.
}

Revista de Historia, año 18, vols. 18-19, 2008-2009, pp. 69-78. 
supuestamente conducirian al "orden". a la salvación de Alemania. El "orden" implicaba la climinación de los enemigos ideológicos y políticos (los "traidores" de 1918) y de la "amenaza" racial que amenazaba la supervivencia de "la raza superior".

Sobre este punto se extraña en la mayoría de los trabajos la referencia a al contexto propiamente político y social que permita entender este culto e importancia del militarismo en la sociedad alemana y la responsabilidad que le correspondio a la Republica de Weimar y los Socialdemocratas, que se apoyaron en las fuerzas militares para restringir el alcance de la revolución de noviembre de $1918^{25}$.

\section{LA VIOLENCIA CONTRARREVOLUCIONARIA Y RACIAL}

Acompañando de la militarización pos Gran Guerra como factor explicativo del ascenso de Hitler al poder se encuentra la violencia política. Durante las primeras décadas del siglo XX la política alemana se disputaba, además de en el Parlamento - en las calles. La lucha callejera, el control por éstas marcaba la relación entre la izquierda y la derecha. Uno de los grupos paramilitares de derecha era el Freikorps que lanzó su violencia contra el alzamiento revolucionario espartaquista (Der Spartakusaufstand) de 1918, jugando un rol en los asesinatos de Rosa Luxemburgo y Karl Liebknecht, además, por cierto de participar en el aplastamiento de la efímera República Socialista Bávara (Bayrische Răterepublik) de ese año. Los miembros de estas organizaciones paramilitares, toleradas por al República de Weimar, cran los soldados licenciados que no estaban dispuestos a retomar la vida civil y ofrecian sus servicios a terratenientes u organizaciones conservadoras.

Existe meridiano acuerdo en que la violencia Nazi se oriento claramente en dos frentes: el político que significaba reducir a las organizaciones de Izquierda que habían experimentado un importante crecimiento desde inicios del siglo 26 y el racial antisemita.

Sobre las razones y objetivos de la violencia dirigida a los sectores de izquierda, la lógica es relativamente clara, impedir que la revolución socialista se instaurara en Alemania y por ello los Nazis contaron con las simpatías de bastos sectores conservadores, industriales, terratenientes, incluidos sectores del catolicismo, entre otros 27 .

El tema racial antisemita ha sido uno de los más resaltados por los estudios, incluso desde antes del ascenso de Hitler al poder la prensa norteamericana señalaba la agresividad y violencia racial de los Nazis. como una de sus caracteristicas. En 1922 el New York Times informaba:

"Los desfiles de Hitler, principalmente bajo la bandera antisemita, que es atractiva para muchas personas ajenas a las filas de su partido. Baviera en la actualidad está impregnado de animosidad a los judíos, y esta sensación constantemente surge en una conversación en las vías públicas en los trenes y lugares similares. Gran parte del antagonismo es notablemente dirigido sin embargo, no contra los judíos residentes, pero en contra de los procedentes de fuera del Estado" 28 .

Desde una perspectiva comparada el racismo nazi es para Kershaw y Kallis un elemento central y característico de los nazis (en relación al fascismo italiano), parte de la particularidad "ünica" del régimen nacionalsocialista 29 . Pero si bien comparativamente este elemento resulta central y dramático, en especial desde la noche de los cristales rotos el 9 y 10 de noviembre de 1938, la situación de violencia organizada y planificada parece haber sido dirigida centralmente hacia las fuerzas políticas enemigas de los nazis.

Así, el tema en torno a la importancia que el racismo anti - semita tenía dentro del NSDAP antes de 1933 es complejo, pues si bien se reconoce la importancia de este factor dentro de la política Nazi existen matices en su relevancia para su política hacia el poder total. Bessel señala que:

"El problema, es que mientras el NSDAP fue claramente un partido racista con un programa claramente racista y si bien las consecuencias más horribles de la captura de nazi de poder consistian

25 Sobre esto ver: Parker. R. A. C. Op. cit, pp 347,350, Contemporaneo a los acontecimientos encontramos la critica a la politica del Partido Comurista Aleman y a la Tercera Internacional en Trotsky, L. Stafin, El gran organizador de derrotak, pp. 75-79.

2h El crecimiento del voto dentro de la izquierda alemana esta bien graficado en Parker. R. A. C. Op. cit, p. 252. La responsabilidad que correspoodio a los Socialdemocratas (SPD) y Cotnunistas (KPD) en su derrota electoral de 1932, es un tema que supera este trabajo, pero sobe el que hay señalar que los antecedentes deben ser buscados tanto en la participación de los Socialdemócratas en la República de Weimar, como en la politica aislacionista del KPD dirigida desde Moscú.

27. Ver: Poulantzas, N. Op. cit.

a The New York Times, 28 de noviembre de 1922. "Hitler parades primarily under the anti-Semitic bannes, which is attractive to many outsiders the ranks of his party. Havaria at present is steeped in animosity to the Jews, and this feeling constantly crops up in conversation in the public thoroughfares on the trains and similar places. Much of the antagonism is noticeably directed however, not against the resident Jews, but against those coming here from outside the State".

29 Ver, Kershaw: L. Op ett, p. 241; y Kallis, A. Op. ctr, p. 25. 
precisamente en hacer real la ideología racista nazi, el racismo no parece haber desempeñado un papel principal en como Hitler lograr el poder. Como ya se ha observado, aunque el prejuicio racial y el odio contra los judíos motivo a muchos activista nazi para dedicarse al movimiento. los millones de seguidores pasivos que alimentaron con su voto los éxitos electorales de la NSDAP parecen haber sido motivados principalmente por otras preocupaciones. Lo mismo puede decirse con respecto a la violencia política que acompañó los éxitos nazis en los inicios de la década de 1930 y la captura del poder en 1933: los principales objetivos de las Sturmabteilung [SA] fueron los opositores políticos a los nazis - en la primera instancia los comunistas y los socialdemócratas y sus aparatos institucionales (oficinas de los sindicatos, periodicos y similares) - en lugar de los judfos. Por supuesto a que los judios no huyeron de la atención de las Stumabteilung: sin embargo, los ataques contra judíos en este momento parecen casi algo como una idea posterior, una salida extra para la agresión, en comparación con los ataques contra los partidarios de la izquierda*30.

La violencia previa a 1933, los enfrentamientos políticos y raciales, como prolongación interior de la Primera Guerra Mundial y sus consecuencias internas ocuparon un lugar importante en la constitución de las nociones de liderazgo dentro del partido nazi ${ }^{31}$. Este periodo, definido dentro de los nazis como el "tiempo de la lucha" (Kampzeit), moldeó el entendimiento de la política como un enfrentamiento, donde lo civil o los consensos quedaba fuera de consideración y donde el enemigo socialista, comunista o judío debía ser "exterminado". Desde esta perspectiva la "Guerra Total"32 se libraba al interior de la sociedad alemana, antes de que Hitler y sus seguidores decidieran exportarla a toda Europa ${ }^{33}$.

Se puede señalar que la "Guerra Total" tenía sus ensayos en el contexto europeo occidental, pues la violencia nazi se inseribió en la lucha que el fascismo desarrolló contra los sectores socialistas. Para el profesor de la Universidad de Bristol. Aristotle Kallais el miedo a la revolución socialista era fácil de manipular como una "reserva negativa de integración socio política" 34 .

"Sin embargo, si la 'amenaza' socialista fue considerada como un grave inconveniente sociopolítico hasta 1917, la revolución bolchevique en Rusia convirtió los temores vagos en una visión apocalíptica paneuropea inminente. Secuestrados por la paranoia, grandes sectores de los electores nacionalistas y las elites conservadoras vieron sospechosamente (aunque erróneamente) eventos como la revolución de noviembre de 1918 en Kiel, el biennio rosso en Italia y las huelgas generales en Gran Bretaña como un ensayo para la embestida del internacionalismo comunista en Europa. Incluso si la amenaza no se materializó finalmente (y en el final de la década de 1920 esto se había convertido en aparente, incluso para la mayoria de los alarmistas observadores de derecha de la inter-war), continuó ofreciendo una reserva potente y fácil-a-manipular de integración sociopolítica negativa,

Los movimientos fascistas desempeñan un papel lider e instrumental en los violentos esfuerzos para frenar la 'amenaza socialista'. Ellos organizados o participando en los grupos paramilitares, (squadri en Italia, Freikorps y SA en Alemania, Stahlhelm en Austria, legionarios en Rumania, Greenshirts en Francia, por nombrar sólo la de los más conocidos) orientados contra la agitación Socialista emulando técnicas de sus oponentes (los sindicatos, violencia callejera, movilización masiva de partidarios). En la defensa de los fundamentos de orden existente contra la subversión de izquierda y subrayando valores conservadores, como el orden, la unidad nacional y la protección del status, los movimientos fascistas emergieron como aliados naturales (e inesperados) de los mecanismos represivos del Estado en el asalto al socialismo organizado" 35 .

Al considerar la violencia nacionalsocialista como uno de los factores políticos centrales de su existencia es posible apuntar que el ascenso del nazismo al poder se relacionaba con las dificultades que los proyectos socialistas y comunistas enfrentaban en Europa y que se pueden relacionar tanto con las diversas reacciones "contrarrevolucionarias" al interior de cada país y con la política exterior de la Unión Soviética

* Bessel, R. Op cit. p. 175. (Traducción del Autoe)

24 Ver Goebel, S. Op. it. p. 198.

32 Ver: Hobsbawm. E 2006. Historia del Siglo XX., Barcelona, Critica.

33 Pero la jucha no se habia limitado a enfrentar a la izquierda pues desde el fracaso del alzamiento de 1923 y la pérdida de relevancia de la idea de "marcha sobre Berlin", el propio NSDAP fue escenario de una lucha interna y con otras organizaciones derechistas, como el Partido Nacional del Pueblo Alemain (DVNP). Hacia 1925 las diferencias eran resueltas a favor del NSDAP. Ver: Noakes, I. 1966. "Conflict and Deveiopment in the NSDAP 1924-1927", en Joumal of Contemporary History. VoL. 1. $\mathrm{n} * 4$, pp. 5 y ss. Dentro de las organizaciones Naxis lan SA fueron golpeadas (purgas) en 1934 (Noche de los cuchullos largos) por la centralización del partido y la búsqueda de Hitler por el apoyo del ejercito Alemán (Reichsweior).

T4. Kallis, A. Op. cit p. 18

35. Ibidem, pp, 18-19.

Revista de Historía, año 18 , vols. 18-19,2008-2009, pp. 69-78. 
dirigida por $\operatorname{Stalin}^{36}$

\section{EL ORDEN Y LA FALSIFICACIÓN SISTEMÁTICA DEL PASADO}

Si la violencia ocupaba un lugar dentro de la dinámica socio-politica alemana particularmente en las ideas de los nazis, esta violencia se inscribió en un contex to que les favorecía pues los sectores conservadores en la cabeza del Estado necesitan aplacar las fuerzas que ponían en jaque al autoritarismo conservador presente en la República de Weimar y donde los tres cancilleres anteriores a Hitler (Brüning, Papen y Schleicher) habían fracasado en fortalecer un orden autoritario que excluyera a los socialdemócratas y a los sindicatos y que al mismo tiempo brindara estabilidad. ${ }^{37}$ La búsqueda del orden era, por cierto una necesitad para la mantención de las relaciones de poder sociales y económicas existentes.

El "orden" era un objetivo central para los sectores dominantes de Alemania toda vez que la crisis económica y el desempleo habían penetrado en los partidos políticos generando una profunda polarización política. Empresarios y militares del alto mando eran quienes anhelaban el establecimiento de la disciplina y orden social. ${ }^{38}$ El Ejército (Reichswehr) era tal vez la institución donde los cuadros de alto mando estaban más interesados en impedir el desorden social, la revolución y la guerra civil. Pero este interés no significó un apoyo a las aventuras putshistas de algunos de sus miembros. Tal como Parker apunta dentro del ejército no existía la idea de asumir el control total del Estado ${ }^{39}$ sino más bien de apoyar a quien asegurara la mantención del orden. Hitler entendió esto después del fracaso del putsh de 1923 en Baviera, iniciando un continuo acercamiento al aparato militar del Estado. Lo continuaria criticando pero ya no lo enfrentaría. Una vez en el poder Hitler se encargó de devorar a quienes lo instalaron en $\mathrm{el}^{40}$.

En este contexto la invitación de enero de 1933 de Hitler al gobierno fue posible no solamente por la debilidad de carácter que afectaba a Hindenburg sino por que además dentro de las esferas de poder del Estado y la elite alemana existía la convicción de que podrían controlar a Hitler y a la masa que lo seguía, de que el orden podría ser mantenido ${ }^{41}$. En este sentido los trabajos lan Kernshaw muestran la responsabilidad que para el futuro inmediato de Alemania y Europa (previo a la Segunda Guerra Mundial) tuvieron las decisiones, envidias, conspiraciones, etc., de pequeñas camarillas de poder. ${ }^{42} \mathrm{La}$ importancia de la obra de Kernshaw, no debe hacer olvidar que los grandes personales y las élites si bien son relevantes se insertan en contextos mayores, como la crisis política y económica, las consecuencias de Versalles, etc. Brindar importancia a esos elementos generales y de contexto ha sido uno de los elementos más presentes en el debate historiografico al interior de Alemania.

Desde la perspectiva de Hobsbawm el orden ofrecido por Hitler aseguraba la eliminación de la "amenaza" socialista. En la implantación del nuevo régimen no se postulaba una revolución (que tampoco se dio) pues en Alemania, al igual que en Italia, los extremistas de derecha llegaron al poder por conveniencia o iniciativa del viejo régimen. ${ }^{43}$ Así, a juicio de Hobsbawm, el nazismo no levantó un nuevo régimen sino que revitalizó el antiguo ${ }^{44}$. Al plantear esto el historiador británico lanza una crítica a las interpretaciones "liberales" que ven revoluciones en los triunfos del fascismo.

La búsqueda del orden político y social se combinó de manera particular con un interés por el orden en un plano socio-cultural, el orden nórdico y/o germánico, donde el pasado se transformó en objeto de culto. Un supuesto tiempo perdido debía ser rescatado para salvar el presente y el futuro de Alemania. Este factor se expreso en lo que Hobsbawm cataloga como una invención de tradiciones, un conjunto de ideas absurdas, donde "la raza destinada a dominar el mundo con Hitler ni siquiera tuvo un nombre hasta 1898 cuando un antropólogo acuño el termino 'nórdico' 45

\footnotetext{
36. Ver: Lewin, M. 2005, El siglo soviético _Qué sucedido nealmente en la Unión Sovieffica?, Barcelona, Critica; Poulantzas, N. Op. Cit.

97. Bessel R. Op. cit, p. 184.

16 Ibid, p. 186

39 Parker. R. A. C. Op, cit, pp. 252 y ss.

40 Hobsbawm, E. Op. cit. pp. 126 y ss.

4 La humillación sufrida por Hitler en el proceso judicial de 1931 pudo significar un sintoma de incapacidad y facilidad de manipular para a los ojos de elite alemana que confio en Hitler. Ver: Carter, B. 2008. El Hombre que humillo a Hitler, Barcelona, Ediciones B.

42. Ver: Kernshaw, L. Hitier... Tambièn en el historiador estadunidense Henry Turner. 1996. Hitier3 Thirty Days to Power: January 1933 , Reading, Mass, Addison-Wesley.

4. Hobsbawm, E. 2006. Historia del Stglo XX, Barcelona, Critica, pp, 132-133,

4 Ibid, p. 134 .

4. Hobsbawm, E. Op. cit, p. 125. Es necesario apuntar algunas ideas del historiador estadounidense Bernatd Mess ya que su interpretación cornparte la opinión de Hobsbawm de invención de tradiciones: sectores del mundo académico e intelectual fueron responsables de esta invención de un pasade que supuestamente avalaba a la raza superior en su lucha por el predominio europeo y mundial. Bernar Mess en "Hitler and Germanentum"
}

Revista de Historia, año 18, vols. 18-19, 2008-2009, pp. 69-78. 
Para el profesor de la Universidad de Kent en Canterbury, David Welch en "Nazi Propaganda and the Volksgemeinschaft: Constructing a People's Community" 46 la construcción de la "comunidad nacional" (Volksgemeinschaft) fue presentada como trascendente a las divisiones sociales y se anclo en una "nueva unidad étnica basada en los 'verdaderos' valores Alemanes" ${ }^{* 47}$. En este sentido Welch observa - a diferencia de Hobsbawm - que uno de los importantes elementos "revolucionarios" estaba en el objetivo nazi de lograr con la Volksgemeinschaft una verdadera armonía de clases ${ }^{48}$.

Para el logro de su objetivo el NSDAP desarrolló una importante actividad de propaganda que planteaba a los dirigentes del Partido "educar al pueblo en la ideología nazi y cuidarlos en orden de prevenir otro 1918 (...) proveyendo el liderazgo del pueblo en todas las esferas de la vida en acuerdo con su ideologia ${ }^{349}$.

\section{LA BASE MATERIAL: DESEMPLEO Y CRISIS}

Desde la perspectiva de Hobsbawm, el elemento explicativo y casual de mayor relevancía para entender el desarrollo y posicionamiento del nazismo en particular y del fascismo general es la Gran Depresión de 1929 y sus efectos 50 . Desde su perspectiva,

"el fascismo no habria alcanzado un puesto relevante en la historia universal de no haberse producido la Gran Depresión. Italia no era por sí sola un punto de partida lo bastante sólido como para conmocionar al mundo. En los años veinte, ningún otro movimiento europeo de contrarrevolución derechista radical parecía tener un gran futuro, por la misma razón que había hecho fracasar los intentos de revolución social comunista: la oleada revolucionaria posterior a 1917 se había agotado y la economía parecía haber iniciado una fase de recuperación" 51 .

El periodo de relativa estabilidad económica entre 1924 y 1928 dio resultados electorales bastante pobres al partido nazi, Pero cuatro años más tarde (1932) era el partido más grande de Alemania. Tal como lo apunta Bessel, de los millones de votantes de 1932 no se puede decir que todos fueran racistas o antisemitas 52 , por lo cual el problema (además del silencio de los votantes nazis a los planteos antisemitas del NSDAP 53 ) apunta al peso del factor económico como catalizador de fenómenos políticos, sociales y culturales 54 .

El conjunto de elementos sociales culturales, como los efectos de la guerra; el culto al militar, la violencia política y racial; la obsesión con el orden y la falsificación del pasado, no eran suficientes para dar

apunta que el intereses por el pasada por una antigüedad alemana que asignaba un carácter diferencial al "pueblo germinice", aludide por Hitler en Mi Lucha, estuvo particularmente asociado a los miembros de la derecha más radicalizada. Importantes academicos alimentaron los mitos nacienalistas extremos, entre estos Mess sehala a Hermann Gúnter, decano de la Facultad de Filosofia de la Universidad de Heilderberz: el arqueólogo Gustaf Kossinna el historiadot Andreas Heusler. Mess observa que hacia 1870, la noción de "germanidad" (Germanention) era usada como optsesto a "Judeidad" (Judenthans). la "germanidad" era una forma "metafisica de cardcter, derivada de la esencia de la raza nórdica, que se revela a si misma como un poder creativo basado en la sctítud heroica localizada en la personalidad como la única representación de la existencia organica del pueblo (vôlkisch)":

Esta supuesta beroicidad ancestral se presentaba coma la justificación de un orden germainco con derechos sobre otros pueblos y territorios europeos, Kossinna en su interpretación del pasado arqueologico fue uno de los que alimentó la noción de "espacio vital" (Lebeneraum) planteando que antiguos asentamientos germínicos en Europa del este validaban el dominio germánico sobre la población eslava.

En el estudio de Mess se aprecia que Hitler no siempre estuvo tonalmente de acuerdo con la idea de volver al pasado germánico, aunque sí se establece que siendo el mismo un fabricante de mitos fue un idealizador del pasado. En 1921 en una caracterizaciónt del Estado Alemàn el futuro dictador usaba la "germanidad" como opuesta a la "judeicidad", denunciando que la estructura estatal y comercial era más "judia" que "germánica". Ver: Mess, B. 2004. "Hitler and Germanentun" (Hitler y la Germanidad, en journal of Contemporary History, vol. 39 (2), pp. 255-170.

46 En: Journal of Contemporary History Vol, 39 (2), 2004. pp. 213 - 238.

4 Welch, D. "Nazi Propaganda and the Volksgemeinschaft: Constructiong a People's Community", en Op, cit.. P. 213.

48 Ibid, 214 .

40 Noakes, 1. "The Nazi Party and German Society", en lournal of Contemporary History, vol 39 (2), p. 196.

so Hobsbawm, E. Op. ctt., p.136.

si Idern

52. 'Central-Verein deutscher Staatsburger jidischen Glaubens. Ortsgruppe Koln'. Cologne, November 1930, in Arnold Paucker, Der jiidische Abwehrkampf gegen Antisemitismus und Nationalsozialismus in den letzten lahren der Weimarer Republik (2nd edn. Hamburg 1968). 194. En Bessel, R. Op, cit, p. 170 .

39. Idem.

34 El problema de iquiénes votaron por los nazis? resulta interesante y se observa una mayor votación en los estados del norte de Alernania (Schleswig - Holstein; Oldenburg. Prusia, etc.), no asi en el sur (Baviera). Además las ciudades con alto nümero de trabajadores tampoco parecen haher entregado sus votos en mayoría ul los nazis, a diferencia del peso nazi en las zonas agricolas. En el estudio y ecomprensión de este fenómeno electoral se consideran diversos elementos: clase, confesión religiosa (los protestantes dieron más votos a los nazis que los católicos) y los diversos intereses regionales (donde elementos de clase, religión y propiedad se mezclaban). Ver: O'Laughlin, 3. Flint, Anselin. C. 1994. "The Geography of the Nazi Vote: Context, Confession, and Class in the Reichstag Election of 1930'. En: Annals of the Association of American Geographers, Vol. 84, No.3, pp. 351-380. También en Parker, R. A. C. Op. cit.

Revista de Historia, anto 18, vols. 18-19, 2008-2009, pp-69-78. 
fuerza al nazismo en Alemania. Ya que fue la crisis la que sembraba la paranoia en los sectores conservadores y derechistas y que les hacia desear el orden, toda vez que movilizaba a los sectores de izquierda, se puede encontrar en la situación económica.

También se encuentran elementos más profundos y estructurales del desarrollo económico y político de Alemania que están directamente ligados al proceso de industrialización llevado adelante desde la Bismark, que la había dado la oportunidad a las elites prusianas conservadoras de mantener el poder sobre las decisiones de materia económica constituyéndose una alianza entre los industriales liberales y las elites terratenientes del este del Elba que aseguró una centralización del progreso económico acompañado de un conservadorismo político 55 .

El nazismo (al igual que el fascismo italiano), además de cuestionar a su "enemigo natural" el comunismo y a los sectores de izquierda, lanzó críticas al liberalismo y la democracia que según la derecha radical capitalista era responsable de abrir las puestas al movimiento obrero. Las críticas económicas eran bastante ambiguas ${ }^{56}$ y la relación y existencia de la propiedad privada según Peter Temin estuvo en directa relación con los acuerdos que los propietarios establecieran con los objetivos del NSDAP57, Dentro de la economía nazi el control completo sobre las actividades productivas y el uso del terror para el logro de esto fue parte de su agenda.

El desempleo fue uno de los elementos económicos que tuvo especial importancia en la configuración de un clima favorable para la campaña nazi. La República de Weimar no logró frenar los problemas económicos, el crecimiento del déficit y el desempleo. El salto del desempleo fue dramático de poco menos de un millón trescientos mil en el verano de 1929 a más de seis millones a inicios de $1932^{58}$. A lo cual se sumó una de las mayores caídas en los salarios reales sufridas en Europa 59 .

¿Por qué fueron los nazis y sus aliados los favorecidos con el clima de crisis y no así los sectores de izquierda y particularmente los comunistas?, esta es una interrogante que debe buscar respuesta no solamente al interior de Alemania sino que además en la política dirigida desde Moscú. Pero por cierto este es un tema mayor que supera los límites de estos apuntes.

\section{CONCLUSIÓN}

Como se puede apreciar nuestra aproximación al pasado de configuración de la toma del poder por parte de Hitler en 1933 debe considerar una serie de elementos que superan la tradicional ( $y$ aún importante) explicación centrada en las resoluciones de Versalles y la Paz de París. La historiografía británica ha tendido a reflejar este enriquecimiento que es a la vez expresión de una nueva mirada europea sobre si misma, que con mayor o menor éxito intenta alejarse de los estereotipos construidos en la primera década del siglo XX.

Alemania durante la República de Weimar fue escenario de la profundización del culto militar. agudizado por la extrema derecha a partir de la derrota de la Gran Guerra. Este culto al militar, al soldado, se puede ligar al ascendente que logró tener Hitler no sólo como frontsoldat sino que también como "personificación del régimen". Junto al culto a lo militar se gestó una memoria mítica de la guerra que buscó "culpables" de la "humillación" en la izquierda, quienes fueron presentados como traidores de una inversión del siglo XIX: la "raza" y su destino superior. En la discusión de estos mitos la propaganda sistémica, la falsificación histórica fue la herramienta nazi.

Pero estos factores no fueron los precipitantes sino que se vieron catalizados por la crisis económica y política que sembraba el pánico en los sectores de la derecha, temerosos de una revolución socialista. Así los nazis aparecieron y se presentaron como guardianes del orden conservador establecido desde la unificación liderada por Bismark. $\mathrm{Y}$ en el establecimiento del orden la violencia no fue un fenómeno nuevo pues desde el

\footnotetext{
55 Veri Van Riel, A, y Shram, A. 1993. "Weimar Economic Decline, Nazi Economy Recovery and the Stabilization of Political Dictatorship", en: Jouernal of Economic History, Vol. 53, n* 1, pp. 74-76.

56 Sobre la relación entre la ideologia faseista y nazi con el liberalismo y capitalismo existe una interesante discusión que supera por sa amplitud los limites de este trabajo. Sobre este tema ver, entre otros; Roberts, D. 2000. "How Not to Think about Fascism and ldeology, Intellectual Antecedents and Historical Meaning", en Journal of Comtemporary History, VoL, 35, No. 2), pp. 185-211; Sternhell, Z. 2003. Los origenes del fascisme iraliano, Barcelona, Editorial Siglo XXI; Kallis, A. Op. cit.

57. Temin, P. 1991. "Soviet and Nazi Economic Planning in the 1930s", en The Economic History Review, New Series, Vol, 44 (4), pp. 573-593.

sa Dimsdale, N., Horsewoor, N. y Van Riel, A. 2006. "Unemployment in Interwar Germany. An Analysis of the Laboe Market, 1927-1936", en The Journal of Economic History, Vol, 66 (3), p. 778.

50 Idem.
} 
fin de la primera guerra la militarización, polarización político y agudización de falsificaciones socioculturales había sentado los antecedentes del paramilitarismo anti-izquierdista y anti-semita.

En todo esto Hitler es visto como elemento central o expresión de fenómenos estructurales, el debate sobre su rol seguro continuará. Así como el estudio de este periodo de crisis y gestación de miseria humana seguirá estando en las discusiones académicas y en la memoria europea, aquella memoria que funcionó, hasta cicrto punto, como advertencia para la búsqueda de la unidad.

\section{BIBLIOGRAFIA}

Blackbourn, D. 1986. "The Polítics of Demagogy in Imperial Germany", en Past and Present, N" 113 , pp. 152-184.

Bessel, R. "The Nazi Capture of Power", en Journal of Contemporary History, Vol. 39, (2).

Carter, B. 2008. El Hombre que humillo a Hitler, Barcelona, Ediciones B.

Dimsdale, N., Horsewoor, N. y Van Riel, A. 2006. "Unemployment in Interwar Germany: An Analysis of the Labor Market, 1927-1936", en The Journal of Economic History, Vol. 66, número 3.

Fisher, F. 1961. Griff nach der Weltmacht. Die Kriegsszielpolitik des kaiserlichen Deutschland 1914/1918, Duisserldorf.

Goebel, S. 2004. "The 'Sleeping Dead" in Interwar and Britain". En: Journal of Contemporary History. Vol. 39 (4), pp, 497-501.

Hobsbawm, E. 2006, Historia del Siglo XX, Barcelona, Crítica.

Judt, T. 2005. Postguerra. Una historia de Europa desde 1945, Madrid, Taurus.

Kallis, A. 2004. "Consensus'Ideological Production, Political Experience and the Quest for Studying InterWar Fascism in Epochal and Diachronic Terms", en European History Quarterly. 34 (9).

Kershaw, 1. 2004, "Hitler and the Uniqueness of Nazism", en Journal of Contemporary History, Vol. 39 (2), pp. 239-254.

Kershaw I. 2007. Hitler, Barcelona, Editorial Península, 2 tomos,

Lewin, M. 2005. El siglo soviérico ¿Qué sucedió realmente en la Unión Soviética?, Barcelona, Crítica.

Mess, B. 2004. "Hitler and Germanentun" (Hitler y la Germanidad), en Journal of Contemporary History, vol. 39 (2), pp. 255-170.

Noakes, J. 1966. "Conflict and Development in the NSDAP 1924-1927", en Journal of Contemporary History.

Vol. 1, número 4, pp. 3-36.

Nolte, E. 1967. El fascismo en su época, Barcelona, Edicions 62.

Sabrow. M. et all. 2003. Zeit Geshichte als Streitgeschichte Grossen Kontroversen seit 1945, Munich, Editorial C.H. Beck.

Parker, R. A. C. 1978. El Siglo XX. Europa, 1918-1945, México, Siglo XXI Editores,

Populantzas, N. 1976. Fascismo Y Dictadura. La Tercera Internacional Frente Al Fascismo, Barcelona, Editorial Siglo XXI.

Temin, P. 1991. "Soviet and Nazi Economic Planning in the 1930s", en The Economic History Review, New Series, Vol. 44 (4), pp. 573-593.

Thompson, A. 1994. "Honours Uneven: Decorations, the State and Bourgeois Society in Imperial Germany", en Past and Present, 144, pp. 171-204.

Trotsky, L. Stalin. El gran organizador de derrotas.

Turner.1996. Hitler's Thirty Days to Power: January 1933, Addison-Wesley, Reading Mass.

Welch, D. 2004. "Nazi Propaganda and the Volksgemeinschaft: Constructiong a People's Community", en Journal of Contemporary History, Vol, 39 (2), pp. 213-238.

Van Riel, A. y Shram, A. 1993. "Weimar Economic Decline, Nazi Economy Recovery and the Stabilization of Political Dictatorship", en Journal of Economic History, Vol. 53 (1), pp. 71-105. 